\title{
Cyclotrichium niveum (dağ nanesi) esansiyel yağının buğday samanı in vitro sindirilebilirliğine ve rumen mikrobiyal fermantasyonuna etkisi
}

\section{Effect of Cyclotrichium niveum (mountain mint) essential oil on in vitro digestibility of wheat straw and rumen microbial fermentation}

\section{Zeynep ŞAHAN ${ }^{1 *}$ iD}

Adıyaman Üniversitesi, Kahta Meslek Yüksekokulu, Veterinerlik Bölümü, Adıyaman/Türkiye

${ }^{1}$ https://orcid.org/0000-0001-7878-5117

To cite this article:

Şahan, Z. (2021). Cyclotrichium niveum (dağ nanesi) esansiyel yağının buğday samanı in vitro sindirilebilirliğine ve rumen mikrobiyal fermantasyonuna etkisi. Harran Tarım ve Gıda Bilimleri Dergisi, 25(4): 526533.

DOI: $10.29050 /$ harranziraat.989528

*Address for Correspondence: Zeynep ŞAHAN

e-mail:

zysahan@gmail.com

Received Date:

01.09 .2021

Accepted Date:

25.10.2021

(C) Copyright 2018 by Harran University Faculty of Agriculture. Available on-line at www.dergipark.gov.tr/harranziraat öz

Bu çalışmada Cyclotrichium niveum uçucu yağının farklı dozlarının (0, 50, 100 ve $150 \mathrm{mg} \mathrm{L}^{-1}$ kültür sıVısı) rumen mikrobiyal fermantasyonu ve buğday samanının in vitro gerçek sindirilebilirliği üzerindeki etkilerini değerlendirmek amaçlanmıştır. Bu amaçla 40:60 konsantre yem ile beslenen fistüle inekten alınan seyreltilmiş rumen sıvısında buğday samanı 48 saat Daisy inkübatörde inkübe edilmiştir. Elde edilen sonuçlara göre tüm Cyclotrichium niveum esansiyel yağı dozlarının, buğday samanının in vitro HS (ham selüloz), OM (organik madde) ve NDF (nötr deterjan lif) sindirilebilirliğini önemli ölçüde artırdığı $(P<0.001 ; P<0.01$ ve $P<0.001)$ belirlenmiştir. Buğday samanı kuru madde sindirilebilirliğinin (KMS), Cyclotrichium niveum uçucu yağı ilavesinden etkilenmediği görülmüştür ( $P>0.05)$. Cyclotrichium niveum esansiyel yağının, rumen fermantasyonu son ürünlerini olumsuz yönde etkilediği; ölçülen rumen uçucu yağ asitleri miktarlarının (UYA: asetat, propiyonat, butirat, izobütirik asit, valerat ve izovalerat) kontrol grubuna kıyasla önemli ölçüde azaldığı saptanmıştır $(P<0.001 ; P<0.01)$. Cyclotrichium niveum esansiyel yağının ilavesinin, rumen sıvısındaki $\mathrm{CO}_{2}$ miktarını önemli ölçüde düşürdüğü $(\mathrm{P}<0.001)$, rumendeki $\mathrm{CH}_{4}$ gazının, kontrol grubuna kıyasla 50 ppm'lik muamele grubu dışında tüm diğer muamele gruplarında önemli ölçüde azaldığı belirlenmiştir ( $P$ <0.001). Sonuç olarak, Cyclotrichium niveum esansiyel yağının tüm dozları ile rumen fermentasyon parametrelerinin son ürünleri önemli ölçüde azalırken, rumen $\mathrm{pH}$ 'ının arttığı $(P<0.05)$, buğday samanı ile inkübe edilen Cyclotrichium niveum esansiyel yağının buğday samanının in vitro sindirilebilirliklerini ve işkembenin genel fermantasyon sürecini önemli ölçüde etkilediği görülmüştür.

Anahtar Kelimeler: Cyclotrichium niveum, Sindirilebilirlik, Buğday samanı, Esansiyel yağ

\section{ABSTRACT}

In this study different doses $\left(0,50,100\right.$, and $150 \mathrm{mg} \mathrm{L}^{-1}$ of culture fluid) of Cyclotrichium niveum essential oil was incubated 48 hours with wheat straw in diluted ruminal fluid takes from fistulated cow fed with a 40:60 concentrate:forage diet in order to assess the effects on rumen microbial fermentation and in vitro true digestibility of wheat straw. True digestibility of wheat straw was determined in ANKOM Daisy Incubator. All doses of Cyclotrichium niveum significantly increased the in vitro CF (crude fiber), OM (organic matter) and NDF (neutral detergent fiber) digestibility of wheat straw $(P<0.001 ; P<0.01$ and $P<0.001)$. Dry matter digestibility (DMD) of wheat straw was not statistically affected by Cyclotrichium niveum essential oil $(P>0.05)$. Cyclotrichium niveum essential oil negatively affected end-products of rumen fermentation; the value of the measured rumen volatile fatty acids (VFA: acetate, propionate, butyrate, isobutyric acid, valerate and isovalerate) significantly decreased compared to the control group $(P<0.001 ; P<0.01)$. The addition of Cyclotrichium niveum essential oil significantly reduces the $\mathrm{CO}_{2}$ in rumen fluid $(P<0.001)$. $\mathrm{CH}_{4}$ gas in the rumen was significantly reduced in all treatment groups except the $50 \mathrm{ppm}$ 
treatment group compared to the control group $(P<0.001)$. While end-products of rumen fermentation parameters significantly decreased with all doses of Cyclotrichium niveum essential oil, rumen $\mathrm{pH}$ has increased $(\mathrm{P}<0.05)$. As a result it was observed that Cyclotricium niveum essential oil incubated with wheat straw significantly affects the in vitro digestibility of wheat straw and the overall fermentation process of rumen.

Key Words: Cyclotrichium niveum, Digestibility, Wheat straw, Essential Oil

\section{Giriş}

Ülkemizde hayvansal üretimde antibiyotiklerin yasaklanmasıyla birlikte, bitki özleri, alternatif yem katkı maddeleri büyüme uyarıcıları olarak önem kazanmaya başlamıştır. Bitkisel ekstraktların ve yağlarının hayvansal üretimde kullanım potansiyelini araştırmak için son zamanlarda bu konu ile ilgili çalışmalar yoğunluk kazanmıştır (Kim ve ark., 2019). Rumende mikrobiyolojik aktiviteyi etkileyen sarsoponin, tannin, timol gibi ikincil metobolitler üretebilen bitkiler, kullanım için değerli potansiyele sahip alternatif yem katkı maddeleri olarak kabul edilmektedirler (Benchaar ve ark., 2015). Bitkilerden elde edilen esansiyel yağların gram (+) ve gram (-) bakteriler üzerine antimikrobiyal etkileri bulunmaktadır. Araştırıcılar esansiyel yağların antibakteriyel etkilerini nasıl gösterdiklerine dair birçok mekanizma rapor etmişlerdir. Bunlardan biri esansiyel yağların hidrofobik özellikleri ile açıklanmıştır. Esansiyel yağların hidrofobik özellikleri sayesinde bakterilerin hücre ve mitokondri lipid membranlarını etkileyerek yapılarını bozduğu bunun da hücre geçirgenliğini etkileyerek hücre içi iyon dengesinin bozulmasına neden olduğu bildirilmektedir (Ultee ve ark., 2002; Lambert ve ark.,2001). Ayrıca esansiyel yağlar bazı proteinlerin hidrofobik kısımlarını etkileyerek ve bu etki sonucu dekorboksilaz enzimi gibi önemli enzimleri işlevsiz bırakarak da antibakteriyel özelliklerini göstermektedir (Wendakoon ve Sakaguchi, 1995).

Esansiyel yağların rumende protein parçalanmasını, patojenik mikroorganizmaların kontrolünü, sindirim enzimlerinin aktivitesini ve azot emilimini arttırdığını bununla birlikte gübrelerin neden olduğu çevre kirliliğini azalttığını bildiren çalışmalar mevcuttur (Gill, 2001; Wallace ve ark., 2004; Cardozo ve ark., 2005; Chaves ve ark., 2008; Patra ve Yu, 2012; Önenç ve ark., 2016; Belanche ve ark., 2019).

Esansiyel yağların rumen fermantasyonu üzerine düzenleyici etkileri ile ilgili birçok çalışmada görülen değişkenlikler; genel olarak kullanılan bitkinin kimyasal bileşimlerine, esansiyel yağın dozuna, rumen $\mathrm{pH}$ 'sına ve rasyon içeriğine bağlıdır. (Cardozo ve ark., 2005; Calsamiglia ve ark., 2007). Esansiyel yağların uygulandığı dozun rumen fermantasyonu üzerine etkisine bakıldığında; düşük ve orta dozlarda kullanıldığında rumen mikrobiyal ekosistemi üzerinde etkisiz veya seçici olarak etkili olmakta iken, yüksek dozlarda kullanıldığında rumen fermantasyonu üzerinde genel bir inhibitör etki (UYA'larını azaltıcı, metan oluşumunu azaltıcı) gösterdikleri bildirilmektedir (Yadeghari ve ark., 2015).

Cyclotrichium niveum (dağ nanesi), yoğun beyaz trikom, güçlü nane kokusu ve Lamiaceae familyasına ait 20-50 cm yüksekliğinde bir yıllık otsu bir bitkidir. Birçok çalışmada Cyclotrichium niveum esansiyel yağının antimikrobiyal ajanlar (pulegone germacrene-D,

menthone, isomenthone ve spathulenol) açısından zengin olduğu bildirilmiştir (Gulcin ve ark., 2008; Alim ve ark., 2009; Gürsoy ve ark., 2009). Cyclotrichium niveum'un gram (+) bakterilerden Staphylococcus aureus, Staphylococcus epidermidis, Staphylococcus saprophyticus, Staphylococcus warneri, Staphylococcus xylosus,Micrococcus luteus, Bacillus cereus, Bacillus subtilis ve Streptococcus pneumoniae ile gram(-) bakterilerden Escherichia coli, Citrobacter freundii, Citrobacter koseri, Enterobacter aerogenes, Neisseria lactamica, Neisseria sicca, Proteus vulgaris, Proteus mirabilis, Pseudomonas aeroginosa, Pseudomonas fluorescens, Klebsiella pneumonia ,Klebsiella oxyttoca gibi bakterilere karşı antimikrobiyal etkisinin olduğu bildirilmişitir (Gülçin ve ark.,2008). Cyclotrichium niveum'un 
antimikrobiyal özellikleri nedeniyle, rumendeki mikroorganizmaları

etkileyerek

rumen

fermantasyonunun manipüle edilmesinde etkili olabileceği beklentisi mevcuttur. Başka bir deyişle, mikrobiyal protein sentezini teşvik etmede, proteinlerin yaygın olarak parçalanmasını önlemede, metan üreten bakterileri kontrol etmede, selüloz sindiren bakterilerin çoğalmasını uyarmada ve aside neden olan bakterileri baskılamada etkili olabileceği düşünülmektedir. Mevcut çalışmada Cyclotrichium niveum yapısındaki bir monoterpen olan pulegone (\%32) gibi aktif bileşenleri aracılığı ile rumen mikroorganizmalarını etkileyerek rumen fermantasyonunu değiştirebileceği öngörüsü çalışmanın hipotezini oluşturmaktadır. Bu çalışmada, ruminant hayvanlarda bir yem katkı maddesi olarak Cyclotrichium niveum (Boiss.) Manden ve Scheng'in (dağ nanesi) kullanım potansiyeli ve etkili dozu in vitro olarak araştırılmıştır.

\section{Materyal ve Metot}

Denemede yürütülen işlemler Çukurova Üniversitesi Hayvan Deneyleri Yerel Etik Kurulu tarafından onaylanmıştır $(26.08 .2014,2014 / 05-$ 12). Çalışmada kullanıma yetecek miktarda Cyclotrichium niveum (dağ nanesi) bitkisi ağustos ayında toplanmış ve serin bir ortamda direk güneş ışınlarına maruz bırakılmaksızın gölgede kurutulmuştur. Daha sonra bitkinin kuru yaprakları uçucu yağ eldesi için buhar distilasyon yöntemi ile ekstrakte edilmiş olup, kuru yapraklarda uçucu yağ oranı \% 2.5-3.0 arasında değişim göstermiştir. Distilasyon sonrası elde edilen yağ, koyu renkli cam şişelere alındıktan sonra, inkübasyon ve kimyasal analizlerde kullanılmak üzere $+4 \quad{ }^{\circ} \mathrm{C}$ 'de saklanmıştır. Çalışmada Cyclotrichium niveum uçucu yağı aktif bileşenlerinin analizi için N-hexane ile seyreltildikten sonra 1:20 oranında elde edilen uçucu yağları GC-MS analizi, Agilent $30 \mathrm{~m} 0.250 \mathrm{~mm}$ * $0.25 \mathrm{m \mu}$ marka GC-MS cihazında DB-5MS boyutunda, $1 \mathrm{ml} \mathrm{dak}^{-1}$. helyum gazı akış hızı, 1:50 bölünme oranı, $250^{\circ} \mathrm{C}$ giriş sıcaklığı, $1 \mu$ l enjektör hacmi, $60^{\circ} \mathrm{C}^{\prime}$ de başlayan, $3^{\circ} \mathrm{C}$ dak ${ }^{-1}$. Isıtma $300^{\circ}$ C'ye getirilerek ve 5 dakika bekledikten sonra analiz sonlandırılmıştır. Analiz sonucu dağ nanesinin içerdiği en fazla aktif bileşenlerin yüzdesi pulegon (\% 31.9), germacren-D ( $\%$ 16.45), menthone (\% 15), izomenthone $(\%$ 9) ve spathulenol (\% 3.5) olarak bulunmuştur.

Cyclotrichium niveum'un buğday samanının in vitro gerçek sindirilebilirliği üzerine etkileri ANKOM Daisy inkübatörü ve teknolojisi kullanılarak değerlendirilmiştir. Çalışmada kullanılan inkübatör 4 kavanozdan oluşmaktadır ve her bir doz (Kontrol 0ppm, 50 ppm, ve 100ppm) ayrı kavanozlarda denenmiştir. İnkübasyonlarda buğday samanı örneklerinden 0.75 gr tartılarak hazırlanan 22'şer adet torba 3'er adet boş torbayla birlikte herbir inkübasyon kavanozunda toplam 25 'er adet torba olarak inkübe edilmiştir Her kavanoza 2 It'lik inkübasyon sıvısı (1600 ml tampon solusyonu $+400 \mathrm{ml}$ rumen sIvısı) CO2 tüpü eşliğinde ilave edildi ve yine $\mathrm{CO} 2$ tüpü eşliğinde her muameleden 0, 50, 100 ppm'in karşılığı olacak miktarlarda Cyclotrichium niveum (Boiss.) Manden \& Scheng (dağ nanesi) bitkisinin yağı ilgili kavanozlara eklendi. In vitro inkübasyonlarda kullanılan rumen sıvısı kaba:kesif yem oranı 60:40 olan rasyon ile beslenen kanüllü kısır bir inekten (ortalama ağırlığı 500 kg olan Siyah-Alaca) alınmıştır. Rumen sıvısı alımı hayvanın sabah yemlemesinden 3 saat sonra gerçekleştirilmiş, daha sonra $\mathrm{CO}_{2}$ tüpü eşliğinde alınan rumen sıvısı, yine $\mathrm{CO}_{2}$ tüpü eşliğinde süzüldükten sonra $39^{\circ} \mathrm{C}^{\prime} \mathrm{de}$ termosta muhafaza edilmiştir. Buğday samanı, kimyasal analiz ve inkübasyon için $2 \mathrm{~mm}$ 'lik bir elek kullanılarak öğütülmüştür. Filtre torbalarına (F57) yaklaşık $0.75 \mathrm{~g}$ öğütülmüş buğday samanı tartılmış ve torbaların ağzı ısıtılmış tel yardımıyla mühürlenmiştir. Ağzı kapatılan torbalar 1:4 oranında rumen sıvısı:tampon sıvı ile Daisy" inkübatörde (ANKOM Technology Corp., Macedon, NY) 50, 100 ve 150 ppm dozları karşılayacak miktarda Cyclotrichium niveum esansiyel yağı ile $39.8{ }^{\circ} \mathrm{C}$ 'de anaerobik koşullar altında 48 saat boyunca inkübe edilmiştir. Deneyde, buğday samanı ve inkübasyondan çıkan torbalarda kalan rezidülerin besin madde analizi AOAC (2007) 'de 
belirtilen yöntemlere göre belirlenmiştir. Nötr deterjan lifi (NDF) ve asit deterjan lifi (ADF), sırasıyla Van Soest ve Wine (1975) ve Van Soest (1963) tarafından tarif edilen reaktifler kullanılarak ANKOM fiber analizörü ile analiz edilmiştir (Çizelge 1).

Rumen sıvısındaki uçucu yağ asidi (UYA) içeriğinin belirlenmesi, $45-230^{\circ} \mathrm{C}$ sıcaklık aralığında yarı kılcal FFAP kolonu (Hewlett-Packard, Wardbronn, Almanya) olan bir gaz kromatografisi kullanılarak gerçekleştirilmiştir.

Buğday samanının 48 saatlik inkübasyonundan sonra kalan rumen sıvısında belirlenen uçucu yağ asitlerinin değerleri kullanılarak in vitro fermentasyon ile oluşan karbondioksit $\left(\mathrm{CO}_{2}\right)$ ve metan $\left(\mathrm{CH}_{4}\right)$ gazları aşağıdaki formül ile hesaplanmıştır (Blümmel ve ark., 1999).

Karbondioksit, $\mathrm{CO}_{2}=$ Asetik asit $/ 2+$ Propiyonik asit / $4+1.5 \times$ Butirik asit

Metan, $\mathrm{CH}_{4}=$ (Asetik asit $+2 \times$ Butirik asit) $-\mathrm{CO}_{2}$ (UYA konsantrasyonu mmol olarak alınmıştır)

Elde edilen veriler SAS (1998) paket programı kullanılarak deneme modeline göre varyans analizine tabi tutulmuştur. Ortalamaların karşılaştırılması Duncan Çoklu Karşılaştırma Testi kullanılarak yapılmıştır.

Çizelge 1. Çalışmada kullanılan buğday samanının besin madde içeriği (KM bazında)

Table 1. Nutrient ingredient of wheat straw used in the study (DM basis)

\begin{tabular}{lr}
\hline İçerik ingredient & $\%$ \\
\hline Kuru Madde Dry Matter & 91.89 \\
Organik Madde Organic Matter & 85.80 \\
Ham Protein Crude Protein & 2.85 \\
Ham Kül Ash & 6.09 \\
Ham Yağ Ether Extract & 1.82 \\
ADF & 50.34 \\
NDF & 72.52 \\
Azotsuz Öz Maddeler Nitrogen Free Extract & 8.58 \\
\hline
\end{tabular}

\section{Araştırma Bulguları ve Tartışma}

Sonuçlar Cyclotrichium niveum uçucu yağının buğday samanının in vitro gerçek kuru madde sindirilebilirliği (KMS) dışındaki sindirilebilirliklerini (organik madde sindirilebilirliği (OMS), nötral deterjan lifi sindirilebilirliği (NDFS) ve ham selüloz sindirilebilirliğini (HSS)) önemli ölçüde etkilediğini göstermiştir (Çizelge 2). Buğday samanının kuru madde sindirilebilirliği Cyclotrichium niveum esansiyel yağının artan dozu ile artma eğilimi göstermiştir $(P=0.632)$. Buğday samanının sindirilebilirliğinin ölçümündeki en önemli parametrelerden olan HSS ve NDFS Cyclotrichium niveum esansiyel yağının artan dozu ile artmıştır $(P<0.001)$. Buğday samanının in vitro OMS de yine HSS ve NDFS gibi Cyclotrichium niveum esansiyel yağının artan dozu ile artmıştır ( $P$ $<0.01$ ) Buğday samanı lif kaynağı olduğundan KM, OM ve NDF sindirilebilirliğinin artması istenilen bir durumdur. Esansiyel yağların selülozu sindiren bakterilerin çoğalmasının uyarılmasında etkili olduğu yönünde çalışmalar mevcuttur (Benchaar ve ark., 2011; Belanche ve ark.,2016; Orgahi ve ark., 2017). Denemede elde edilen bulgular göz önünde bulundurulursa, Cyclotrichium niveum uçucu yağının selüloz sindirilebilirliğini artırması daha önce yapılmış çalışmaları destekler mahiyettedir.

Buğday samanının in vitro ham selüloz sindirilebilirliği (HSS) kontrol grubunda \% 8.88 iken, HSS değerleri 50 ppm, 100 ppm ve 150 ppm doz grubunda sırasıyla \% 9.25 (\% 4.17 artışla), \% 11.24 (\% 22.59 artışla) ve\% 12.52 (\% 40.91 artışla) olarak ölçülmüştür. İlginç bir şekilde, in vitro organik madde sindirile bilirliklerinde (OMS) ve nötr deterjan lif sindirilebilirliklerinde (NDFS) en düşük değerler kontrol grubunda gözlenmiştir. Bu sonuçlar Cyclotrichium niveum esansiyel yağının rumen sıvısında selüloz sindiren bakteriler üzerinde olumlu bir etkisinin olabileceğini düşündürmektedir. Buğday samanı gibi zor sindirilen ve bunun sonucunda enerji kaybına neden olan kaba yem kaynakları için Cyclotrichium niveum esansiyel yağının yem katkı maddesi olarak kullanımı umut vadedici görülmektedir.

Bitki esansiyel yağlarının, bileşimine, dozuna, elde edildiği bitkinin türüne, rumen $\mathrm{pH}^{\prime}$ sına ve hayvanın tükettiği rasyonun kompozisyonuna bağı olarak rumen sindirilebilirliği ve fermantasyon üzerindeki etkisi hakkında birçok veri bulunmaktadır (Cardozo ve ark.,2004; Malecky ve ark., 2009). Rumen fermantasyonunun tüm nihai 
ürünlerinin substrat yıkımından kaynaklanmadığı varsayılarak, rumen fermantasyonunda gözlenen değişikliğin nedenini açıklamak zordur. Çünkü sindirilebilirlikteki değişimin, rumen mikroorganizmaları tarafından doğrudan kullanılan Cyclotrichium niveum uçucu yağının bir sonucu mu yoksa substrat bozulması ve fermantasyon üzerindeki dolaylı etkisinin sonucu mudur? Bu konuda kesin bilgi vermek mümkün değildir. Bu çalışmada buğday samanının sindirilebilirliğinin artmasına karşın UYA miktarındaki azalmanın açıklanamaması bu durumu desteklemektedir.

Çizelge 2. Cyclotrichium niveum'un buğday samanının in vitro gerçek sindirilebilirliği üzerine etkisi

Table 2. Effect of Cyclotrichium niveum on in vitro true digestibility of wheat straw

\begin{tabular}{|c|c|c|c|c|c|c|}
\hline & \multicolumn{4}{|c|}{ Dozlar Doses $\left(\mathrm{mg} \mathrm{L}^{-1}\right)$} & \multirow{2}{*}{ SEM } & \multirow{2}{*}{$\mathrm{P}$} \\
\hline & 0 & 50 & 100 & 150 & & \\
\hline HSS CFD & $8.88 \mathrm{~b}$ & $9.25 \mathrm{~b}$ & $11.24 \mathrm{a}$ & $12.52 \mathrm{a}$ & 1.04 & $* * *$ \\
\hline KMS DMD & 21.93 & 23.62 & 24.25 & 25.02 & 3.75 & 0.632 \\
\hline OMS OMD & $18.55 b$ & $20.16 a b$ & $24.09 a b$ & $26.17 \mathrm{a}$ & 4.38 & $* *$ \\
\hline NDFS NDFD & $10.20 \mathrm{c}$ & $16.49 \mathrm{~b}$ & $19.42 a b$ & $22.74 \mathrm{a}$ & 2.89 & $* * *$ \\
\hline
\end{tabular}

Her harf (a ve b), dozların $\mathrm{p}<0.001(* * *), p<0.01\left(^{* *}\right)$ ve $\mathrm{p}<0.05\left(^{*}\right)$ düzeyinde birbirinden farklı olduğunu gösterir HSS: Ham selüloz sindirimi KMS: kuru madde sindirilebilirliği OMS: organik madde sindirilebilirliği NDFS: NDF sindirilebilirliği

Each letter $\left(a\right.$ and $b$ ) shows that the doses differ from each other at the level of $p<0.001(* * *), p<0.01(* *)$ and $p<0.05\left(^{*}\right)$.CFD: Crude fiber digestibility DMD: Dry matter digestibility OMD: Organic matter digestibility NDFD: NDF digestibility

Çizelge 3. Cyclotrichium niveum'un Buğday samanının in vitro rumen fermantasyonu üzerine etkisi Table 3. Effect of Cyclotrichium niveum on in vitro ruminal fermentation of wheat straw

\begin{tabular}{|c|c|c|c|c|c|c|}
\hline & \multicolumn{4}{|c|}{ Dozlar Doses $\left(\mathrm{mg} \mathrm{L}^{-1}\right)$} & \multirow{2}{*}{ SEM } & \multirow{2}{*}{$\mathrm{P}$} \\
\hline & 0 & 50 & 100 & 150 & & \\
\hline \multicolumn{7}{|l|}{$\begin{array}{l}\text { Uçucu yağ asitleri } \\
\text { Volatile fatty acids }\end{array}$} \\
\hline TUYA TVFA & 58.99 a & $55.01 b$ & $48.77 \mathrm{c}$ & $43.47 \mathrm{~d}$ & 1.55 & $* * *$ \\
\hline Asetik Acetate & $34.37 \mathrm{a}$ & $32.20 \mathrm{~b}$ & $27.95 \mathrm{c}$ & $25.36 \mathrm{~d}$ & 1.02 & $* * *$ \\
\hline Propiyonik Propionate & $12.70 \mathrm{a}$ & $10.97 \mathrm{~b}$ & $10.87 \mathrm{~b}$ & $10.46 b$ & 0.44 & $* *$ \\
\hline Butirik Butyrate & $7.79 a$ & $7.61 \mathrm{a}$ & $6.82 \mathrm{~b}$ & $5.20 \mathrm{c}$ & 0.32 & $* * *$ \\
\hline İzobutirik Isobutyric & $1.44 \mathrm{a}$ & $1.41 \mathrm{a}$ & $0.98 \mathrm{~b}$ & $0.83 \mathrm{c}$ & 0.03 & $* * *$ \\
\hline Valerik Valerate & $1.37 \mathrm{a}$ & $1.29 \mathrm{~b}$ & $0.93 c$ & $0.81 \mathrm{~d}$ & 0.04 & $* * *$ \\
\hline İzovalerik Isovalerate & $1.33 \mathrm{a}$ & $1.54 \mathrm{a}$ & $1.22 \mathrm{a}$ & $0.83 \mathrm{~b}$ & 0.15 & $* *$ \\
\hline$A / P$ & $2.71 \mathrm{a}$ & $2.94 \mathrm{~b}$ & $2.57 \mathrm{bc}$ & $2.43 \mathrm{c}$ & 0.11 & $* * *$ \\
\hline TUYA TVFA & 58.99 a & $55.01 b$ & $48.77 \mathrm{c}$ & $43.47 d$ & 1.55 & $* * *$ \\
\hline $\mathrm{pH}$ & $6.10 \mathrm{~b}$ & $6.20 \mathrm{ab}$ & $6.20 \mathrm{ab}$ & $6.40 \mathrm{a}$ & 0.06 & $*$ \\
\hline \multicolumn{7}{|l|}{ Gazlar Gases } \\
\hline $\mathrm{CO}_{2}$ & $32.05 a$ & $30.26 \mathrm{~b}$ & $26.92 c$ & $23.09 \mathrm{~d}$ & 0.84 & $* * *$ \\
\hline METAN Methane & $17.91 a$ & $17.16 \mathrm{a}$ & $14.66 \mathrm{~b}$ & $12.66 \mathrm{c}$ & 0.49 & $* * *$ \\
\hline
\end{tabular}

Rumende üretilen UYA'leri, geviş getiren hayvan için ana enerji kaynağını oluşturmaktadır. $\mathrm{Bu}$ nedenle, optimum UYA oranları hayvan performansı için çok önemlidir. Bitki esansiyel yağlarının UYA üzerindeki etkisini araştıran birçok çalışma bulunmakta olup, bunlardan bazıları bitki esansiyel yağlarının UYA oranlarını arttırdığını (Benchaar ve ark., 2007) veya etkilemediğini
(Kamalak ve ark., 2011; Tager ve ark., 2011; Matloup ve ark., 2017; Kim ve ark., 2018) göstermektedir. Ayrıca, bu çalışmada elde edilen sonuçlara benzer şekilde, UYA oranlarının önemli ölçüde azaldığını gösteren çalışmalar da bulunmaktadır (Castillejos ve ark., 2005; Busquet ve ark., 2006). Mevcut çalışmada Cyclotrichium niveum esansiyel yağı takviyesinin, toplam UYA 
üretimi, propiyonik asit, bütirik asit, asetik asit konsantrasyonunu, artan Cyclotrichium niveum dozu ile önemli ölçüde azalttığı gözlemlenmiştir ( $P$ $<0.001$, P <0.05) (Çizelge 3). Bu sonuçlara göre, Cyclotrichium niveum yağı takviyesinin rumen mikrobiyal aktivitesini ve genel fermantasyon sürecini önemli ölçüde engellediği söylenebilir.

Rumende sindirim sonucunda oluşan $\mathrm{CO}_{2}$ ve $\mathrm{CH}_{4}$ gibi gazların miktarı genellikle sindirimdeki artışla ilişkilidir ve rumendeki mikroorganizma aktivitesi hakkında bilgi vermektedir (Hungate ve ark., 1954). Nasab ve ark., (2018), ana bileşeni pulegone (\%38.83) olan bitkinin rumen fermantasyonuna olan etkisini araştırdıkları çalışmalarında; rumende gaz üretimini önemli ölçüde azalttığını gözlemlemişlerdir. Bu çalışmada da kullanılan Cyclotrichium niveum yağında en çok bulunan aktif bileşen pulegondur (\%31.9) ve artan dozlarla gaz üretiminin azaldığı sonucu; Nasab ve ark. (2018) tarafından yapılan çalışma sonuçları ile uyum göstermektedir. Çalışmada Cyclotrichium niveum uçucu yağının, metan $\left(\mathrm{CH}_{4}\right)$ üretimini önemli ölçüde azalttığı görülmüştür $(P<0.001)$. Bu sonuçlar, çalışmada metan üretim öncüleri olan asetatın azalması ile tutarlı görülmektedir. Antimikrobiyal özellikleri nedeniyle uçucu yağlar rumen metanogenezini seçici olarak kısıtlamak için kullanılabilir. Metan $\left(\mathrm{CH}_{4}\right)$, rasyon bileşimi ve yem alımına bağı olarak karbondioksit $\left(\mathrm{CO}_{2}\right)$ ile karşılaştırıldığında 21 kat daha fazla küresel ısınma potansiyeline sahiptir (Bodas ve ark., 2012). Enterik metan kayıpları ruminantlarda brüt enerji alımının \%2-12'si olarak kabul edilir (Boadi ve ark., 2004). Bitki esansiyel yağları kullanılarak $\mathrm{CH}_{4}$ emisyonlarının azaltılması hem hayvanlar (yemden yararlanma oranı ve verimliliğin arttırılması) hem de çevre (sera etkilerinin hafifletilmesi) için yararlı olabilir (Benchaar ve ark., 2011).

Bitki esansiyel yağlarının metan üretimini azalttığını gösteren çalışmaların sayısı oldukça fazla (Günal ve ark. 2017; Agarwal ve ark., 2008; Wang ve ark., 2009; Nasab ve ark., 2018), olup bu çalışmada belirlenen gaz miktarındaki azalma, inkübasyon ortamındaki mikroorganizmaların ve dolayısıyla fermantasyon parametrelerinin uçucu yağdan olumsuz etkilendiğini gösterebilir.
Rumen $\quad \mathrm{pH}^{\prime} \mathrm{sl}, \quad$ rumendeki optimum fermantasyonun sürdürülmesi için çok önemli bir denge faktörüdür. pH'daki değişiklikler, rumendeki mikroorganizma topluluğunun çeşidini ve aktivitelerini, protein ve yağ asitlerinin, özellikle UYA'ların oluşumunu ve emilimini etkilemektedir. Bu çalışmada Cyclotrichium niveum esansiyel yağı, tüm dozlarda ruminal pH'ı arttırmıştır $(p<0.05)$. Bu sonuç Cyclotrichium niveum esansiyel yağının rumende selüloz sindiren bakterilerin uyarıldığı düşüncesini oluşturmuştur zira bu çalışmada Cyclotrichium niveum esansiyel yağı takviyesi buğday samanının NDFS ve HSS'ni arttırmıştır. Bilindiği gibi selüloz sindiren bakteriler bazik ortamlarda asidik ortamlardan daha etkin olmaktadırlar.

\section{Sonuçlar}

Çalışma sonuçlarından, Cyclotrichium niveum uçucu yağ takviyesinin rumen mikrobial aktivitesini ve rumen genel fermantasyon sürecini önemli ölçüde etkilediği görülmüştür. Cyclotrichium niveum esansiyel yağının sindirilebilirlik parametreleri üzerindeki olumlu etkisi buğday samanı gibi sindirimi zor lifçe zengin yem materyelleri ile kullanılabilir potansiyelinin olduğunu düşündürmektedir. Cyclotrichium niveum esansiyel yağının rumen fermantasyon ürünlerinden UYA ve gazlarını azaltıcı etkisinden dolayı; rumende besinlerin enerji kaybının azaltıması ve dolayısı ile çevreye zararlı etkisi olan metan gazı salımının azaltılması amacı ile kaba yem kaynaklarıyla kullanılması önerilebilir. Bununla birlikte hayvancılık endüstrisi için kullanılmadan önce, Cyclotrichium niveum esansiyel yağının hayvan performansı ve takviyenin ekonomi yönü üzerindeki etkisini belirlemek için daha fazla araştırma yapılması gerekmektedir.

\section{Ekler}

Yazar, Adıyaman Üniversitesi Bilimsel Araştırma Projeleri (KMYOBAP/2014-0003) birimine desteklerinden dolayı teşekkür eder. 
Çıkar Çatışması Beyanı: Yazar herhangi bir çıkar çatışması olmadığını beyan eder.

Yazar Katkısı: Makaleye ait tüm çalışmalar Zeynep

ŞAHAN tarafından yapılmıştır.

Etik Beyan: Denemede yürütülen işlemler Çukurova Üniversitesi Hayvan Deneyleri Yerel Etik Kurulu tarafından onaylanmıştır (Çukurova Üniversitesi Hayvan Deneyleri Yerel Etik Kurulu Toplantı Tarihi: 26.08.2014, Toplantı Sayısı: 5, Karar No: 12).

\section{Kaynaklar}

Agarwal, N., Shekhar, C., Kumar, R., Chaudhary, L.C., Kamra, D.N. (2009). Effect of peppermint (Mentha piperita) oil on in vitro methanogenesis and fermentation of feed with buffalo rumen liquor. Animal Feed Science Technology, 148, 321-327.

Alim, A., Goze, I., Çetin, A., Atas, A.D., Vural, N. and Dönmez, E. (2009). Antimicrobial activity of the essential oil of Cyclotrichium niveum (Boiss.) Manden. Et Scheng. African Journal of Microbiology Research, 3, 422-425.

ANKOM Technology. (2005). in Vitro True Digestibility Using the DAISYII Incubator. ANKOM Technology

AOAC. (2007). Official Methods of Analysis. 19th ed. Association of Official Analytical Chemists; Washington, DC

Belanche, A., Kingston-Smith, A.H., Griffith, G.W. and Newbold, C.J. (2019). A Multi-Kingdom Study Reveals the Plasticity of the Rumen Microbiota in Response to a Shift from Non-grazing to Grazing Diets in Sheep. Front Microbiology, 10, 122

Belanche, A., Ramos-Morales, E., and Newbold, C.J. (2016). in vitro screening of natural feed additives from crustaceans, diatoms, seaweeds and plant extracts to manipulate rumen fermentation. Journal of the Science of Food and Agriculture, 96, 3069-3078.

Benchaar, C. (2011). Greathead, H. Essential oils and opportunities to mitigate enteric methane emissions from ruminants. Animal Feed Science Technology, 166, 338-355.

Benchaar, C., Calsamiglia, S., Chaves, A.V., Fraser, G.R., Colombatto, D., McAllister, T.A. and Beauchemin, K.A. (2008). A review of plant-derived essential oils in ruminant nutrition and production. Animal Feed Science and Technology, 145, 209-228.

Benchaar, C., Hassanat, F., and Petit, H.V. (2015). Doseresponse to eugenol supplementation to dairy cow diets: methane production, $\mathrm{N}$ excretion, ruminal fermentation, nutrient digestibility, milk production, and milk fatty acid profile. Animal Feed Science and Technology, 209, 51-59

Boadi, D., Benchaar, C., Chiquette, J., Massé, D. (2004). Mitigation strategies to reduce enteric methane emissions from dairy cows: Update review. Canadian Journal of Animal Science, 84, 319-335.
Bodas, R., Prieto, N., García-González, R., Andrés, S., Giráldez, F.J., López, S. (2012). Manipulation of rumen fermentation and methane production with plant secondary metabolites. Animal Feed Science Technology, 176, 78-93.

Broudiscou, L.P. and Lassalas, B. (2000). Effects of Lavandula officinalis and Equisetum arvense dry extracts and isoquercitrin on the fermentation of diets varying in forage contents by rumen micro-organisms in batch culture. Reproduction Nutrition Development, 40, 431-440.

Calsamiglia, S., Busquet, M., Cardozo, P.W., Castillejos, L. and Ferret, A. (2007). Invited review: Essential oils as modifiers of rumen microbial fermentation. Journal of Dairy Science, 90(6), 2580-2595.

Cardozo, P.W., Calsamiglia, S., Ferret, A. and Kamel, C. (2004). Effects of natural plant extracts on ruminal protein degradation and fermentation profiles in continuous culture. Journal of Animal Science, 82(11), 3230-3236.

Cardozo, P.W., Calsamiglia, S., Ferret, A. and Kamel, C. (2005). Screening for the effects of natural plant extracts at different $\mathrm{pH}$ on in vitro rumen microbial fermentation of a high-concentrate diet for beef cattle. Journal of Animal Science, 83(11), 2572-2579.

Chaves, A.V., Stanford, K., Dugan, M.E.R., Gibson, L.L., McAllister, T.A., Van Herk, F. and Benchaar, C. (2008). Effects of cinnamaldehyde, garlic and juniper berry essential oils on rumen fermentation, blood metabolites, growth performance, and carcass characteristics of growing lambs. Livestock Science, $117,215-224$.

Gulcin, I., Tel, A.Z. and Kirecci, E. (2008). Antioxidant, Antimicrobial, Antifungal, and Antiradical Activities of Cyclotrichium Niveum (BOISS.) Manden and Scheng, International Journal of Food Properties, 11(2), 450471.

Günal, M., Pinski, B., AbuGhazaleh, A. A. (2017) Evaluating the effects of essential oils on methane production and fermentation under invitro conditions, Italian Journal of Animal Science, 16(3), 500-506.

Gursoy, N., Sihoglu-Tepe, A., and Tepe, B. (2009). Determination of in vitro antioxidative and antimicrobial properties and total phenolic contents of Ziziphora clinopodioides, Cyclotrichium niveum and Mentha longifolia ssp. typhoides var. typhoides. Journal of Medicinal Food, 12(3), 684-689.

Hungate, R.E., Fletcher, J.W., Doughery, R.W., and Barrentine, B.F., (1954). Microbial Activity in the Bovine Rumen: Its Measurement and Relation to Bloat. Applied Microbiology, 3(3), 161-173.

Kamalak, A., Canbolat, Ö., Özkan, Ç.Ö., Atalay, A. (2011). Effect of thymol on in vitro gas production, digestibility and metabolizable energy content of alfalfa hay. Kafkas Üniversitesi Veteriner Fakültesi Dergisi, 17(2), 211-216.

Khiaosa-ard, R. and Zebeli, Q. (2013). Meta-analysis of the effects of essential oils and their bioactive compounds on rumen fermentation characteristics and feed efficiency in ruminants. Journal of Animal Science, 91(4), 1819-1830.

Kim, H., Jung, E., Lee, H. G., Kim, B., Cho, S., Lee, S., Kwon, I., and Seo, J. (2019). Essential oil mixture on rumen 
fermentation and microbial community - an in vitro study. Asian-Australasian journal of animal sciences, 32(6), 808-814.

Lambert, R. J., Skandamis, P. N.,Coote,P.J., Nychas, G. J. (2001). A study of the minimuminhibitory concentration and modeofactionof oregano essential oil, thymol and carvacrol. Journal of AppliedMicrobiology,91(3), 453-462.

Malecky, M., Broudiscou, L.P. and Schmidely, P. (2009). Effects of two levels of monoterpene blend on rumen fermentation, terpene and nutrient flows in the duodenum and milk production in dairy goats. Animal Feed Science and Technology, 154, 24-35.

Matloup O, El Tawab AMA, Hassan A, et al. (2017). Performance of lactating Friesian cows fed a diet supplemented with coriander oil: feed intake, nutrient digestibility, ruminal fermentation, blood chemistry, and milk production. Anim Feed Sci Technol, 226, 88-97

Nasab, M.E, Naserian, A.A, Vakili, A.R, Tahmasbi, A.M. (2018). Effect of using Essential Oils of Ziziphora Clinopodioides and Mentha Pulegium As Additive on in vitro Study. Biosciences Biotechnology Research Asia, 15 (1).

Önenç, S.S., Açıkgöz, Z., Kırkpınar, F., Küme, T., Tuğalay, Ç.Ş. and Bayraktar, Ö.H. (2016). Chemical Compositions and Antioxidant Activities of The Essential Oils of Some Medicinal and Aromatic Plants. Journal of Animal Production, 57(2), 7-14.

Ornaghi, M.G., Passetti,R.A.C., Torrecilhas, J.A., Mottin, C., Vital A.C.P., Gurerrero, A., Sañudo, C., Campo, M.M. and Prado, I.N., (2017)Essential oils in the diet of young bulls: Effect on animal performance, digestibility,temperament, feeding behaviour and carcass characteristics. Anim Feed Sci Technol. 234, 274-283.

Patra, A.K. and Yu, Z. (2012). Effects of Essential Oils on Methane Production and Fermentation by, and
Abundance and Diversity of, Rumen Microbial Populations. Applied and Environmental Microbiology, 78(12), 4271-4280.

Tager, L. R., and Krause, K. M. (2011). Effects of essential oils on rumen fermentation, milk production, and feeding behavior in lactating dairy cows. Journal of dairy science, 94(5), 2455-2464.

Ultee, A., Kets, E. P. W., Smid, E. J. (1999). Mechanisms of Action of Carvocrol on the Food-Borne Pathogen Bacillus cereus. Appl. Enviromental Micro., 65, 46064610.

Van Soest, P.J. (1963). The use of detergents in the analysis of fibre feeds. II. A rapid method for the determination of fibre and lignin. Journal of Association of the Official Analytical Chemists, 46, 829-835.

Van Soest, P.J. and Wine, R.H. (1975). The use of detergents in the analysis of fibre feeds. IV. Determination of plant cell wall constituents. Journal of Association of the Official Analytical Chemists, 50, 50-55.

Wallace, R.J. (2004). Antimicrobial properties of plant secondary metabolites. Proceedings of the Nutrition Society, 63, 621-629.

Wang, C.J., Wang, S.P., Zhou, H. (2009). Influences of flavomycin, ropadiar, and 525 saponin on nutrient digestibility, rumen fermentation, and methane emission from 526 sheep. Animal Feed Science Technology, 148, 157-166.

Wendakoon, C. N., Sakaguchi, M. (1995). Inhibition of aminoacid decarboxylase activity of Enterobacteraerogenes by active components in spices. Journal of Food Protection, 58(3), 280-283

Yadeghari, S., Malecky, M., Dehghan Banadaky, M. and Navidshad, B. (2015). Evaluating in vitro doseresponse effects of Lavandula officinalis essential oil on rumen fermentation characteristics, methane production and ruminal acidosis. Veterinary Research Forum, 6(4), 285-293. 